\title{
Effect of Firing Temperature and Porosity on Thermal Conductivity and Diffusivity of Iron Ore Pellets
}

\section{N. S. SUNDARMURTI and Vandana RAO}

Department of Metallurgical Engineering, Faculty of Technology and Engineering, M. S. University of Baroda, Baroda, India 390001.

(Received on January 8, 1996; accepted in final form on April 12, 1996)

\begin{abstract}
The thermal diffusivity and conductivity of iron ore pellet were determined by measuring temperature at surface and centre of pellet during heating and applying heat balance. The effect of firing temperature of pellets and its porosity on thermal conductivity were determined. The mineralogical changes on firing were investigated. The results were analysed by applying model equation and on the basis of basic sintering parameters to determine effective thermal conductivity at zero porosity with radial heat transfer
\end{abstract}

KEY WORDS: thermal diffusivity/conductivity measurements; thermal properties of iron ore pellet; pellet properties; mineralogical changes on heating of pellet.

\section{Introduction}

The knowledge of thermal properties of iron ore agglomerate at higher temperatures are essential to analyse the heat transfer in iron making processes. Wynnyckyj and McCurdy ${ }^{1)}$ examining the induration process observed that a three fold increase in thermal conductivity of pellet resulted in a ten fold increase in their propensity to develop shrinkage cracks. The role of thermal properties and heat transfer on the reaction kinetics of magnetite coalchar composite pellets were emphasised by Seaton ${ }^{2)}$ and co-workers. With these facts in mind an attempt was undertaken to measure thermal properties of iron ore pellets.

Enormous literatures are available to measure thermal properties of materials. The methods used by an investigator was directed by some specific needs and reasons and varied from simple steady state conduction ${ }^{3)}$ method to sophisticated laser flash method. ${ }^{4)}$ Modified laser flash method was reported by $\mathrm{Ohta}^{5)}$ and subsequently used by Akiyama ${ }^{6-8)}$ to measure thermal diffusivities of dense and porous iron ore agglomerates. These non-contact methods are accurate but limited to flat surface geometries and axial heat flow. Abzalov et $a l^{9)}$ also determined the thermal conductivities of small cylinders of compressed magnetite concentrates over a range of temperatures and heating rates.

Measurements of thermal diffusivity and emissivity of fired spherical hematite pellets and dried pellets using transient state conduction equation for radial heat flow were reported by Watt and his co-workers. ${ }^{10,11)}$ They measured the temperatures at half radius and at centre of the pellet by inserting thermocouples to evaluate thermal diffusivity. The insertion of two thermocouples in a small pellet is not desirable specially when effect of factors like porosity or firing temperature are to be investigated.

In the present investigation an attempt has been made to measure the temperature of pellets at surface and centre and apply principles of heat balance to analyse the results. The effect of bulk density and porosity of pellet obtained by firing at different temperatures were investigated. An attempt has been made to explain the results on the basis of existing models and phase changes on heating.

\section{Experimental}

\subsection{Materials}

The lumps of iron ore procured from Rajhara mines of India were crushed and ground to fine size. The size analysis of the powder is indicated in Table 1. Table 2

Table 1. Size analysis of iron ore powder.

\begin{tabular}{clc}
\hline Mesh & Microns & \% Present \\
\hline$-100+170$ & $-152+80$ & 1.90 \\
$-170+200$ & $-88+76$ & 6.00 \\
$-200+300$ & $-76+65$ & 51.50 \\
$-250+300$ & $-65+54$ & 4.50 \\
$-300+$ pan & -54 & 36.10 \\
\hline & Total & 100.00 \\
\hline
\end{tabular}

Table 2. Chemical analysis of iron ore

\begin{tabular}{lc}
\hline Constituent & Percentage \\
\hline Total iron & 64.0 \\
$\mathrm{SiO}_{2}$ & 3.3 \\
$\mathrm{CaO}$ & 1.1 \\
\hline
\end{tabular}




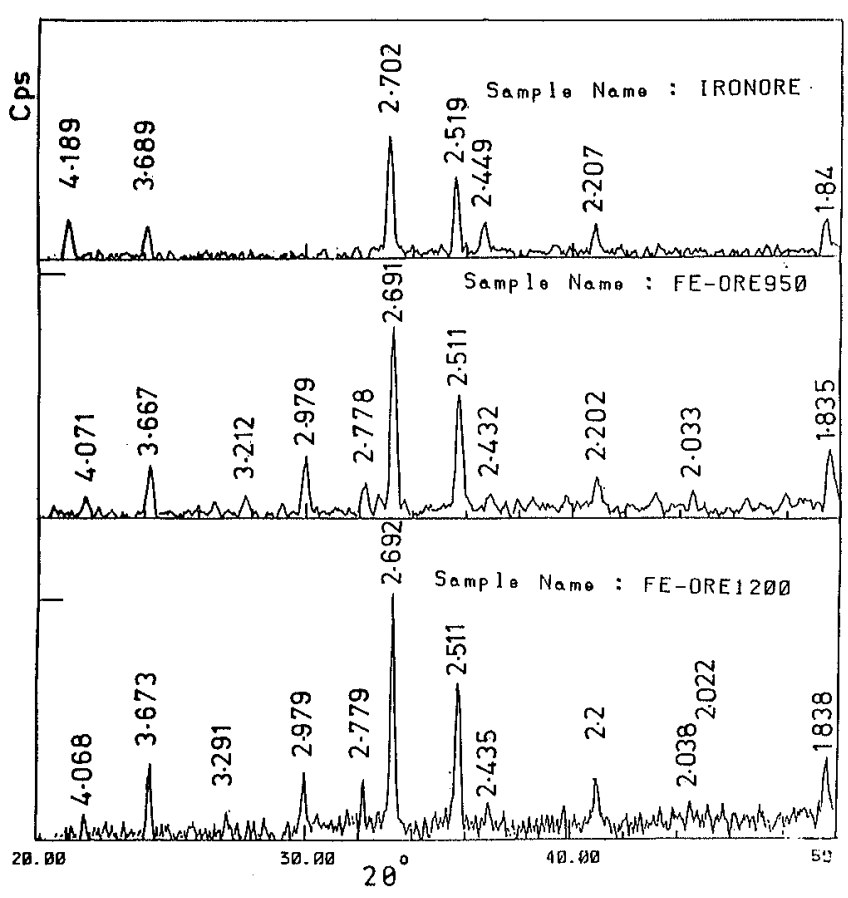

Fig. 1. X-ray diffraction pattern of iron ore, raw and fired.
(a) raw ore
(b) fired at $1223 \mathrm{~K}$
(c) fired at $1473 \mathrm{~K}$

indicates the chemical analysis of the ore. The colour of the ore was orange brown. The X-ray analysis of this ore powder was carried out in Rigaku-D. Max III X-ray diffractometer. The analysis (Fig. 1) indicates the presence of goethite $\left(\mathrm{Fe}_{2} \mathrm{O}_{3} \cdot \mathrm{H}_{2} \mathrm{O}\right)$ along with hematite in the ore. The peaks at ' $d$ ' values of $4.189,2.449$ and at 1.717 represent goethite corresponding to crystal planes of (110), (111) and (221) respectively. The peaks at ' $d$ ' values of $3.689,2.701,2.52,2.207,1.84$ are of hematite. ${ }^{12)}$ The density of the raw powder and its density after firing at higher temperatures, were measured by specific gravity bottle using kerosene as medium.

Pure iron oxide was prepared by precipitation of ferric hydroxide from analytical grade ferric chloride using ammonium hydroxide. The precipitated hydroxide was washed, dried and then fired at $1273 \mathrm{~K}$ for $90 \mathrm{~min}$ to decompose the hydroxide. The completeness of decomposition is confirmed by $\mathrm{X}$-ray analysis.

\subsection{Preparation of Pellets}

The ore powder was pelletised in a disc pelletizer of $0.6 \mathrm{~m}$ diameter and $0.15 \mathrm{~m}$ lip height. One percent dextrin was used as binder. The overall rolling time was about $90 \mathrm{~min}$. The green pellets of size $10-16 \mathrm{~mm}$ and spherical shape were picked, dried at $423-473 \mathrm{~K}$ for $2 \mathrm{hr}$ and then fired at $1223 \mathrm{~K}$ for $1 \mathrm{hr}$ to attain workable strength of pellet. These pellets were furnace cooled. The weight and volume were measured to calculate their bulk densities and porosities. The true density of fine powder was measured by density bottle using kerosene as medium. The pellets of pure iron oxide were made by prolonged hand rolling and then on glass plate.

A radial hole of $0.1 \mathrm{~cm}$ diameter was drilled upto the centre of pellets and classified according to their porosities. The pellets were subsequently fired at temper- atures of $1303,1393,1473,1488,1523$ and $1548 \mathrm{~K}$ for $1 \mathrm{hr}$ in a silicon carbide tube furnace and for higher temperatures in platinum wound tube furnace.

\subsection{Thermal Property Studies}

The method used is similar to one suggested by Watt et al. ${ }^{10.11)}$ with modification and different analysis. The method is selected for its suitability to spherical geometry and radial heat transfer. Watt measured the temperature at half radius and at the centre of the pellet and applied transient conduction equation to evaluate thermal diffusivity. Positioning of a thermocouple at centre and at surface of pellet is more reliable and easier than to place at any radical distance for its accurate positioning. It was reported ${ }^{11)}$ that a ten percent error in positioning of thermocouple at half radial distance gives about twenty percent error in thermal diffusivity values due to sharper temperature profiles. On the other hand, the temperature profile near centre is almost flatter minimising such errors. Moreover, it is not desirable to insert two thermocouples in pellet body specially when the effect of bulk density and porosity needs to be investigated. In view of the above facts, the surface and centre temperature were measured and results analysed by applying principles of heat balance.

In the present setup the pellet is fixed between three chromel-alumel thermocouples so that one thermocouple penetrates the pellet through drilled hole with its bead at the centre. The other two thermocouples are diagonally opposite to the pellet diameter with their beads touching the surface. The insulators are inserted to the wires keeping certain distance from pellet surface. The short circuit between wires is avoided by coating the wire with thin layer of iron oxide (slurry/dried) and maintaining safe distance between two wires. Loose iron ore powder was filled to avoid any air gap between thermocouple and pellet hole. Both the outer thermocouples were tied to a thin walled hollow stainless steel tube containing centre thermocouple and clamped. (Fig. 2)

An independently controlled, preheated tube furnace is lowered on the pellet and the rise in surface and centre temperature of the pellet were recorded by two pen strip chart recorder at a chart speed of $10 \mathrm{~cm} / \mathrm{min}$. Relationship between surface temperature and centre temperature was also recorded in an omniscribe $x-y$ recorder with accurate scale $(1 \mathrm{~cm}=1 \mathrm{mv})$. As tube furnace does not produce an isothermal reservoir but establishes a temperature plateau some where at the centre of the tube, its design is modified, by using reflectors above and below pellet location. These reflectors made of stainless steel are almost of same diameter as the furnace tube. Their use decreases the convective air inspiration, if any, from the bottom of the furnace and also provide configuration similar to an enclosed chamber. It also increases the length of hot zone and variation of temperature within it is decreased. This is also helpful in maintaining the pellet position at the centre of furnace tube. The direct radiation from furnace wall to thermocouple bead was avoided by placing a dome shaped ceramic/metallic shield on the lower reflector to envelop the pellet. This decreases the lateral 
temperature gradient and hence allows to measure surface temperature more accurately. The heat flux passing through the thermocouple wire is likely to cause some error in evaluation of thermal diffusivity. Assuming the thermal contact between the pellet and wire to be sufficiently good to produce similar temperature gradient, it was estimated that error of about $2.5 \%$ in thermal diffusivity value. ${ }^{11)}$ Same order of error may be anticipated in the present case.

\section{Results and Discussion}

Figure 3 indicates the rise in surface (average of two thermocouples) and centre temperature of a pellet with time for one of the sets. The relationship between surface temperature $\left(T_{\mathrm{s}}\right)$ and centre temperature $\left(T_{\mathrm{c}}\right)$ is

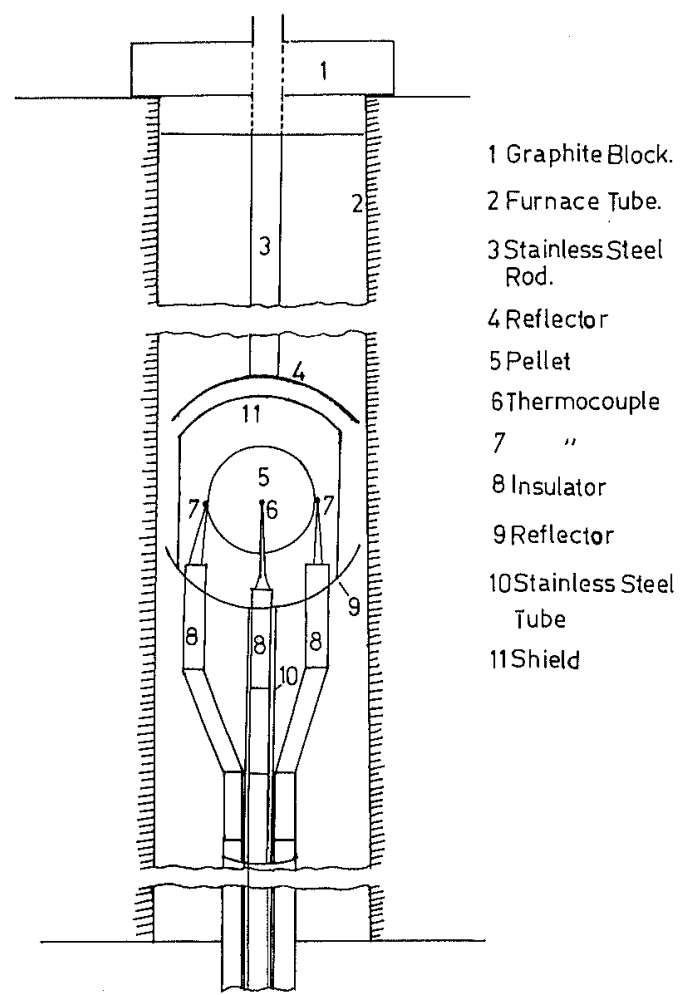

Fig. 2. Location of pellet, thermo couples, reflectors and shield. indicated in Fig. 4.

Attempts were made to correlate ' $T_{\mathrm{s}}$ ' and ' $T_{\mathrm{c}}$ ' with time ' $t$ '. Out of the expressions attempted, the expression of the type

$$
T_{\mathrm{c}}=T_{\mathrm{s}}\left(1-e^{-k t}\right)+T_{\mathrm{o}} e^{-k t}
$$

was found to suit best, ' $T_{\mathrm{o}}$ ' is the initial temperature of pellet and ' $k$ ' is a parameter. Ray et al. ${ }^{13)}$ derived such an equation assuming exponential rate of heating of volume element of sample.

Validity of the Eq. (1) in the present work was tested by plotting a curve between $-\log _{e}\left(\left(T_{\mathrm{s}}-T_{\mathrm{c}}\right) /\left(T_{\mathrm{s}}-T_{\mathrm{o}}\right)\right)$ with time and represented in Fig. 5 for two sets of readings. The linear plot confirms the suitability of the expression for most of the region of heating, except at final stages when ' $T_{\mathrm{c}}$ ' approaches ' $T_{\mathrm{s}}$ ' and the curve tends to be asymptotic. A similar type of expression correlating temperature of a volume element at a radial distance ' $r$ ' can be envisaged as

$$
T_{r}=T_{\mathrm{s}}\left(1-e^{-k^{\prime} t}\right)+T_{\mathrm{o}} e^{-k^{\prime} t}
$$

where $k^{\prime}$ is another parameter.

Relation between $k$ and $k^{\prime}$ is necessary for further analysis of the results and needs to be evaluated.

Taking

$$
k^{\prime}=k(R /(R-r))^{n}
$$

where ' $R$ ' is the radius of the pellet, Eq. (2) modifies to

$$
T_{r}=T_{\mathrm{s}}\left(1-e^{-k t(R /(R-r))^{n}}\right)+t_{\mathrm{o}} e^{-k t(R /(R-r))^{n}}
$$

The above equation satisfies our boundary conditions for any value of ' $n$ '. The value of ' $n$ ' in the present case was determined experimentally. The temperature at surface and the half radial distance $r=R / 2$ were measured during heating of a pure iron oxide pellet when exposed to furnace. Subsequently for the same pellet, a hole of half radius was extended to centre and ' $T_{\mathrm{s}}$ ' and ' $T_{\mathrm{c}}$ ' were recorded. Three runs were taken to check reproducibility in each case. Figure 6 represents the variation of temperature at surface, half radius and at centre of the iron oxide pellet with time. The parameter $k^{\prime}$ and $k$ were evaluated by plotting $-\log _{e}\left(\left(T_{\mathrm{s}}-T_{r / 2}\right) /\left(T_{\mathrm{s}}-T_{\mathrm{o}}\right)\right)$ and $-\log _{e}\left(\left(T_{\mathrm{s}}-T_{\mathrm{c}}\right) /\left(T_{\mathrm{s}}-T_{\mathrm{o}}\right)\right)$ vs. time for this pellet. The

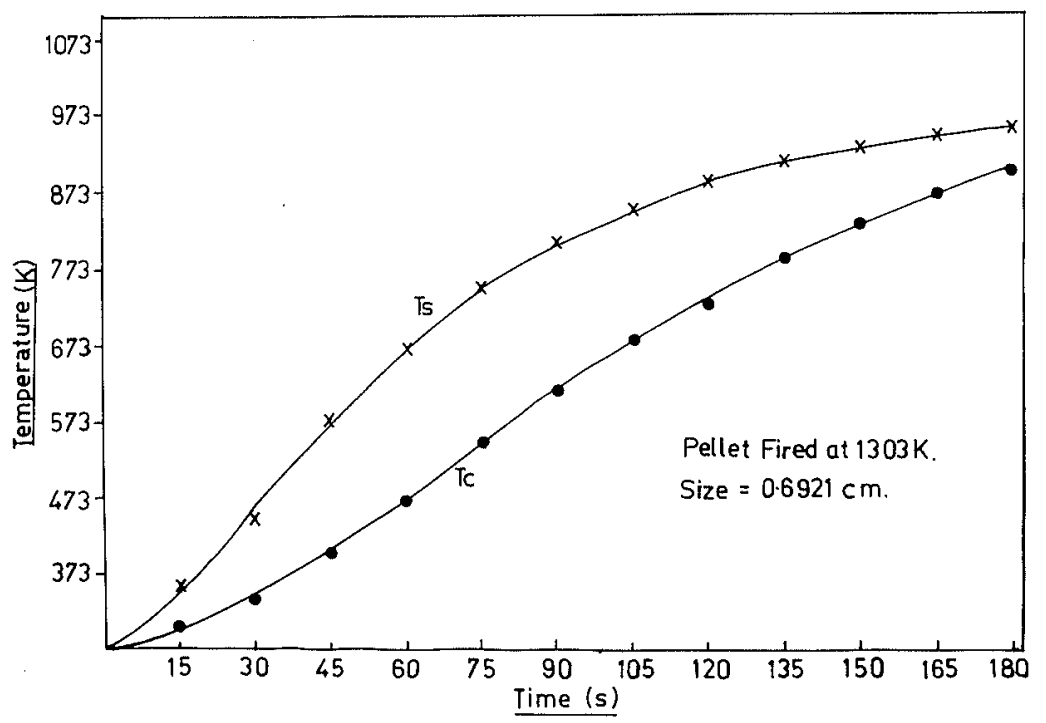

Fig. 3.

Variation of surface and centre temperature of pellet with time. 
results are indicated in Fig. 7. The ratio between the slopes of these two linear plot $k^{\prime} / k$ was found to be 1.238 and the value of ' $n$ ' in Eq. (3) as 0.3 .

Thus the expression modifies to

$$
T_{r}=T_{\mathrm{s}}\left(1-e^{-k t(R /(R-r))^{0.3}}\right)+T_{\mathrm{o}} e^{-k t(R /(R-r))^{0.3}}
$$

on simplification

$$
T_{r}=T_{\mathrm{s}}-\left(T_{\mathrm{s}}-T_{\mathrm{o}}\right) e^{-k t(R /(R-r))^{0.3}}
$$

Ray ${ }^{13)}$ reported that the parameter ' $k$ ' is not a constant but may vary with process conditions. In view of the above the temperature ' $T_{r}$ ' is calculated with instantaneous ' $k$ ' value at any time. The temperature of elements of $1 \mathrm{~mm}$ thickness and with radial distance ' $r$ ' equal to $(R-0.05),(R-0.15),(R-0.25) \cdots$ is calculated using expression (6) for various time intervals. The results for one of the set is indicated in Fig. 8, which in fact, indicate the temperature profile within pellet at various intervals.

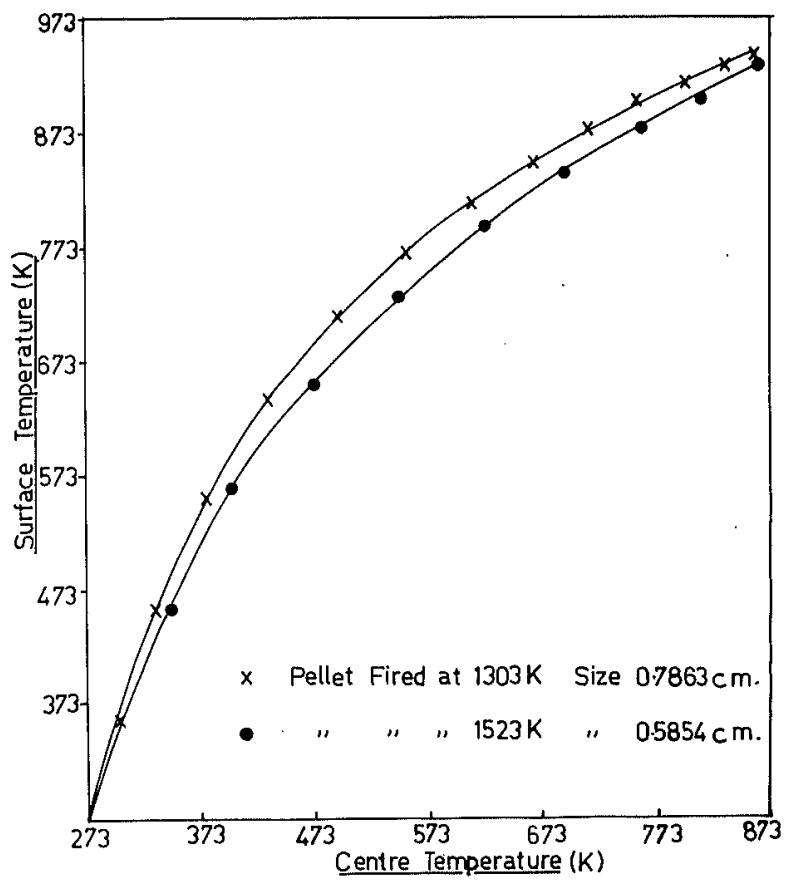

Fig. 4. Relationship between surface and centre temperatures.
The average temperature of pellet at an instant was further calculated by using an expression ${ }^{14)}$

$$
T_{\mathrm{av}}=\frac{\int_{0}^{R} 4 \pi r^{2} T_{r} d r}{\int_{0}^{R} 4 \pi r^{2} d r}
$$

and substituting the value of ' $T_{r}$ ' from Eq. (6) and further integration.

The calculated value of ' $T_{\mathrm{av}}$ ' with time is plotted in Fig. 9 for two sets of experiment and other values are indicated in Table 3.

\subsection{Calculation of Thermal Diffusivity by Heat Balance}

The heat balance at the surface of pellet dictages that amount of heat passing through the pellet surface inside is utilised in heating the pellet.

Thus,

$$
K \cdot A \cdot \frac{d T}{d r}=V \cdot B \cdot C \cdot \frac{d T_{\mathrm{av}}}{d t}
$$

where, $K$ : thermal conductivity of pellet,

$V$ : volume,

$B$ : density,

$C$ : heat capacity, and

$A$ : surface area of pellet.

Rearranging Eq. (8)

$$
\frac{d T_{\mathrm{av}}}{d t}=(K \cdot A /(V \cdot B \cdot C)) \cdot(d T / d r)
$$

substituting for ' $\alpha$ '

$$
\frac{d T_{\mathrm{av}}}{d t}=(3 \alpha / R) \cdot(d T / d r)
$$

The thermal diffusivity $(\alpha)$ can be evaluated for known values of $\left(d T_{\mathrm{av}} / d t\right)$ and $(d T / d r)$. The value of $\left(d T_{\mathrm{av}} / d t\right)$ for various time interval, can be evaluated from ' $T_{\mathrm{av}}$ ', values indicated in Table 3 and Fig. 9. Evaluation of $d T / d r$ is difficult and require certain assumptions. Many expressions relating $d T / d r$ with heat transfer parameter

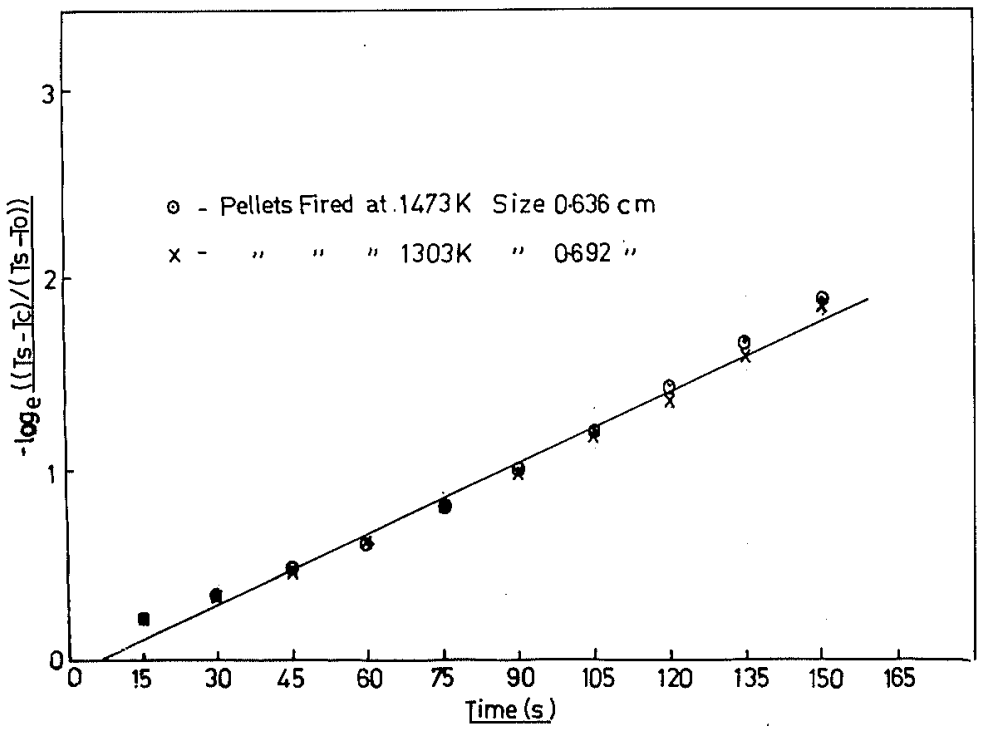

Fig. 5.

Validity of Eq. (1). 


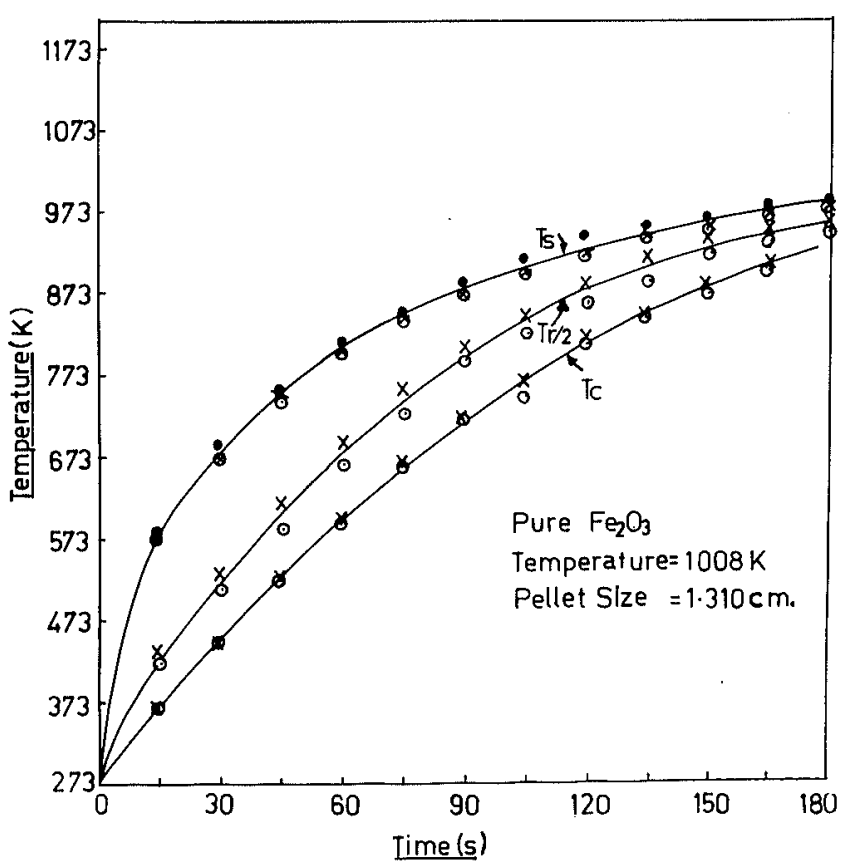

Fig. 6. Variation of surface, half radial and at centre of temperature of pellet with time.

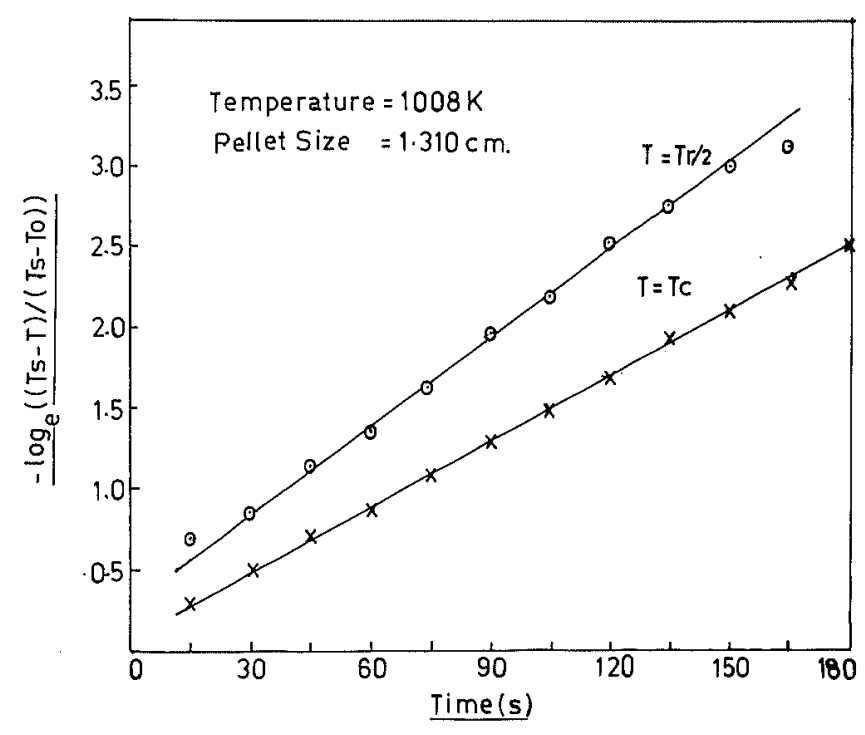

Fig. 7. Evaluation of " $n$ " by ratio of slopes $k, k$ '.

' $\alpha$ ' for different boundary conditions are available in literature. ${ }^{15)}$ These expressions are not useful in present case as the basic aim is to evaluate ' $\alpha$ ' through $d T / d r$. Figure 8 indicates that the thermal profile within the pellet could be approximated to linear except at surface and initial stages of heating. It is also evident that the depth of major temperature fall from $T_{\mathrm{s}}$ to $T_{\mathrm{c}}$, change with time of exposure. Initially the heat front is concentrated at narrow depth near surface and with time it penetrates inside. In present study $90 \%$ of temperature fall from $T_{\mathrm{s}}$ to $T_{\mathrm{c}}$ is assumed at major change and the depth at which it occurs is calculated by Eq. (5) to calculate $d T / d r$. One such model calculation is shown in Table 4. The average of best (7-8) readings are considered to calculate average thermal diffusivity.

The X-ray diffaction analysis of the powder samples heated at $1223 \mathrm{~K}\left(950^{\circ} \mathrm{C}\right)$ and $1473 \mathrm{~K}\left(1200^{\circ} \mathrm{C}\right)$ are given

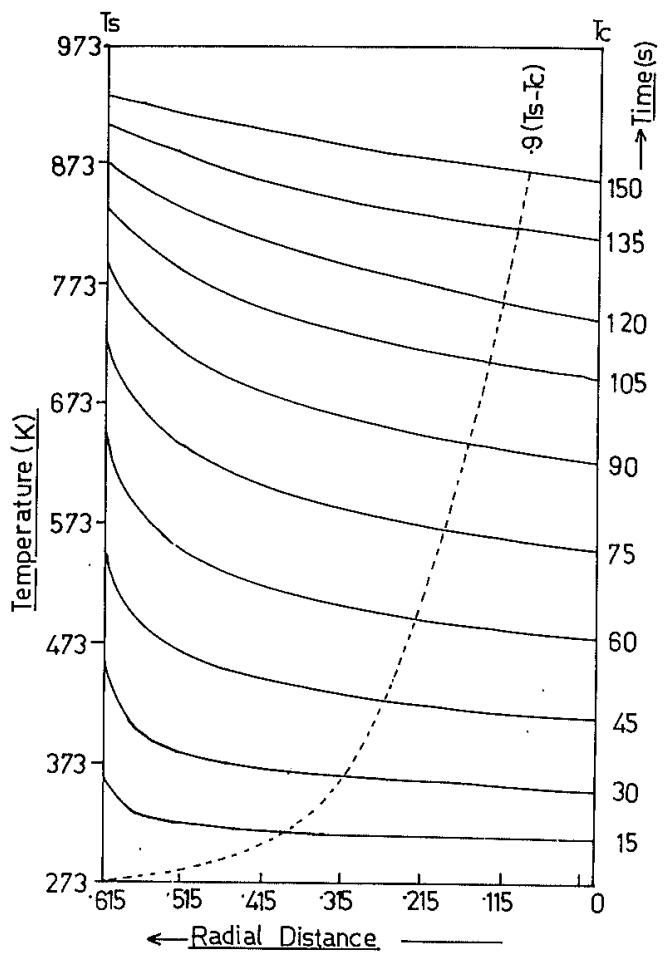

Fig. 8. Temperature profile and movement of heat front $0.9\left(T_{\mathrm{s}}-T_{\mathrm{c}}\right)$ point.

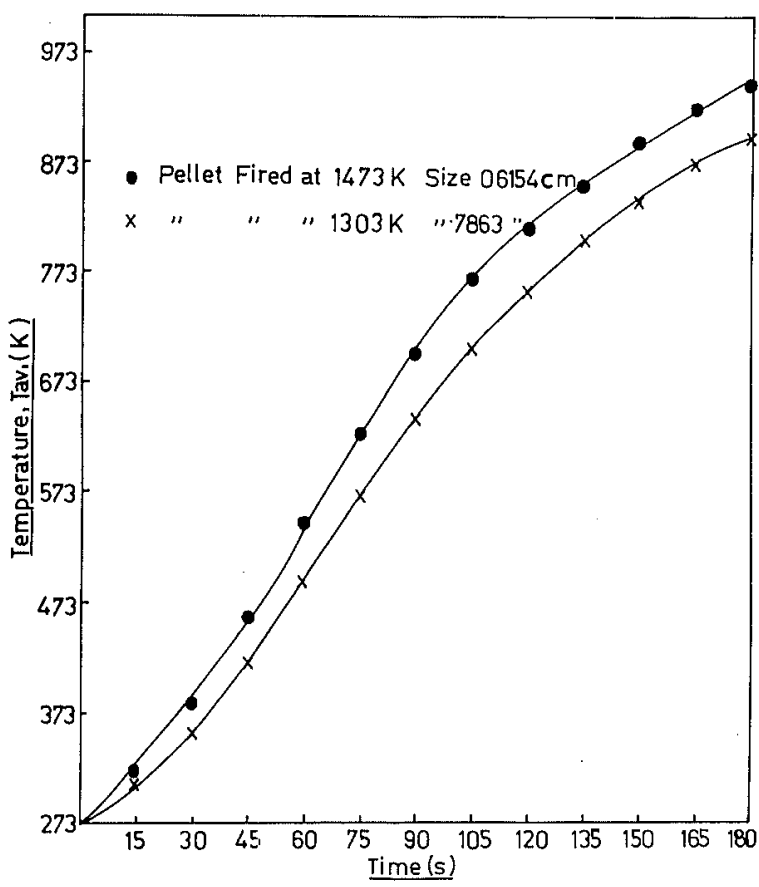

Fig. 9. Average temperature rise of pellet.

in Fig. 1 along with X-ray peaks of raw ore powder. The phase analysis indicates that goethite peak $(d=4.189)$ disappears due to its decomposition which is expected to occur ${ }^{8)}$ between $\left(300-500^{\circ} \mathrm{C}\right)(573-773 \mathrm{~K})$. New peaks at ' $d$ ' values of $4.07,2.98,2.78,2.44$ and 2.03 , matches with $20,100,40$, and $50 \%$ intensity $\left(I / I_{0}\right)$ peaks of $\beta-\mathrm{CaSiO}_{3}$ (Triclinic). ${ }^{12)}$ The equilibrium diagram ${ }^{16)}$ of $\mathrm{CaO}-\mathrm{SiO}_{2}$ system also indicate the possibility of this phase at the temperature and compositions under considerations. Laybidi ${ }^{17)}$ and co-workers working on Kudremukh iron ore observed the mineralogical changes 
Table 3. Average temperature of pellet (Data rounded off to nearest integer).

\begin{tabular}{ccccccccccccc}
\hline $\begin{array}{c}\text { Time } \\
(\mathrm{s})\end{array}$ & 1 & .6921 & .6839 & .6249 & .5854 & .6146 & .6154 & .6921 & .636 & .6294 & .6154 & .7863 \\
& 3 & 2812 & 2914 & 3154 & 3521 & 3650 & 3031 & 2812 & 3057 & 3154 & 3031 & 2654 \\
& 1223 & 1393 & 1488 & 1523 & 1548 & 1473 & 1303 & 1473 & 1488 & 1473 & 1303 \\
\hline 15 & 309 & 311 & 323 & - & 330 & 320 & 313 & 316 & 323 & 321 & 307 \\
30 & 355 & 362 & 377 & 372 & 400 & 380 & 358 & 367 & 369 & 382 & 356 \\
45 & 418 & 431 & 449 & 448 & 474 & 457 & 445 & 451 & 436 & 461 & 418 \\
60 & 489 & 578 & 537 & 534 & 553 & 541 & 530 & 518 & 513 & 544 & 492 \\
75 & 563 & 610 & 622 & 620 & 633 & 626 & 620 & 603 & 593 & 625 & 569 \\
90 & 634 & 692 & 698 & 702 & 703 & 702 & 696 & 680 & 664 & 702 & 639 \\
105 & 698 & 760 & 760 & 768 & 757 & 770 & 763 & 746 & 737 & 766 & 702 \\
120 & 749 & 817 & 821 & 826 & 819 & 823 & 808 & 800 & 793 & 813 & 756 \\
135 & 793 & 865 & 863 & 868 & 855 & 868 & 857 & 845 & 835 & 854 & 801 \\
150 & 829 & 897 & 904 & 908 & 891 & 903 & 892 & 885 & 877 & 891 & 837 \\
165 & 862 & 919 & 926 & 939 & 920 & - & 919 & 915 & 913 & 921 & 872 \\
180 & 886 & 935 & - & 958 & - & - & 938 & 937 & 939 & 942 & 895 \\
\hline
\end{tabular}

1: Size in $\mathrm{cm}, 2:$ Density $\mathrm{kg} / \mathrm{m}^{3}, 3:$ Temperature $\mathrm{K}$,

Table 4. Calculation of thermal diffusivity. Pellet size $0.6291 \mathrm{~cm}$, fired at $1303 \mathrm{~K}, T_{\mathrm{o}}=293 \mathrm{~K}$.

\begin{tabular}{rllllcllll}
\hline Time & $\begin{array}{c}T_{\mathrm{s}} \\
(\mathrm{K})\end{array}$ & $\begin{array}{c}T_{\mathrm{c}} \\
(\mathrm{K})\end{array}$ & $T_{\mathrm{s}}-T_{\mathrm{c}}$ & $T_{\mathrm{s}}-T_{\mathrm{o}}$ & $0.9\left(T_{\mathrm{s}}-T_{\mathrm{c}}\right)$ & $\begin{array}{c}\text { Radial } \\
\text { distance }\end{array}$ & $d T / d r$ & $d T_{\mathrm{av}} / d t$ & $\begin{array}{c}\alpha \\
\left(\mathrm{m}^{2} / \mathrm{s}\right)\end{array}$ \\
\hline 15 & 358.5 & 306 & 52.5 & 65.5 & 47.25 & 0.1889362 & 250.08442 & 2.1667 & $1.998 \times 10^{-7}$ \\
30 & 442 & 366.5 & 105.5 & 149 & 94.95 & 0.2848327 & 333.35357 & 4.4015 & $3.046 \times 10^{-7}$ \\
45 & 573 & 399 & 174 & 280 & 156.60 & 0.3552634 & 440.79969 & 5.7406 & $3.004 \times 10^{-7}$ \\
60 & 665 & 465 & 200 & 372 & 180.00 & 0.4103466 & 438.65356 & 5.8242 & $3.063 \times 10^{-7}$ \\
75 & 745 & 540.5 & 204.5 & 452 & 184.05 & 0.4506661 & 403.03410 & 5.5318 & $3.166 \times 10^{-7}$ \\
90 & 805 & 610 & 195 & 512 & 175.50 & 0.4900077 & 358.15763 & 4.7697 & $3.072 \times 10^{-7}$ \\
105 & 851 & 677 & 174 & 558 & 156.60 & 0.5786412 & 301.94284 & 3.7425 & $2.859 \times 10^{-7}$ \\
120 & 881 & 726 & 155 & 588 & 139.50 & 0.5371069 & 259.72483 & 3.1176 & $2.769 \times 10^{-7}$ \\
135 & 910.5 & 783 & 127.5 & 617.5 & 119.75 & 0.5579178 & 205.67545 & 2.7725 & $3.110 \times 10^{-7}$ \\
150 & 930 & 830 & 100 & 637 & 90.00 & 0.5754939 & 156.38740 & 2.0873 & $3.079 \times 10^{-7}$ \\
165 & 946 & 870 & 76 & 653 & 68.40 & 0.5901223 & 115.90817 & 1.5467 & $3.079 \times 10^{-7}$ \\
\hline
\end{tabular}

(Average: $3.025 \times 10^{-7}$ ).

during firing and reduction. They observed the formation of fayalite bridge between iron ore particles which melts and covers the iron oxide. In the present case no fayalite was observed in X-ray analysis of fired ore. Wynnyckyj and Fahidy ${ }^{18)}$ reported that trivalent iron oxide does not form iron silicate under oxidising conditions, which is in confirmation with our observation. Yank and Standish ${ }^{19}$ ) opined that iron ore sintering is basically a liquid phase sintering process due to the formation of low melting ferrites in presence of basic oxides as $\mathrm{CaO}$. Nasr ${ }^{20)}$ and co-workers also reports the formation of calcium ferrites with their studies on Beharia iron ore pellets. X-ray analysis (Figs. 1(b) and 1(c)) does not indicate the presence of ferrites either, in the present case, probably due to low $\mathrm{CaO} / \mathrm{SiO}_{2}$ ratio. The $\beta-\mathrm{CaO} \cdot \mathrm{SiO}_{2}$ formed in induration of pellets is fairly high melting silicate and formation of liquid phase is not possible under prevailing conditions. In view of above, the present case is a solid state sintering process accompanying mineralogical changes.

The weight loss of the iron ore powder on heating is indicated in Fig. 10. The total weight loss is around $4.2 \%$ and mainly occurs below $1173 \mathrm{~K}\left(900^{\circ} \mathrm{C}\right)$. The decomposition of goethite is expected to be completed around $773 \mathrm{~K}\left(500^{\circ} \mathrm{C}\right)$ or $\mathrm{so}^{8)}$ and hence the continued weight loss upto $1173 \mathrm{~K}\left(900^{\circ} \mathrm{C}\right)$ may be attributed to decomposition of other gangue minerals associated with

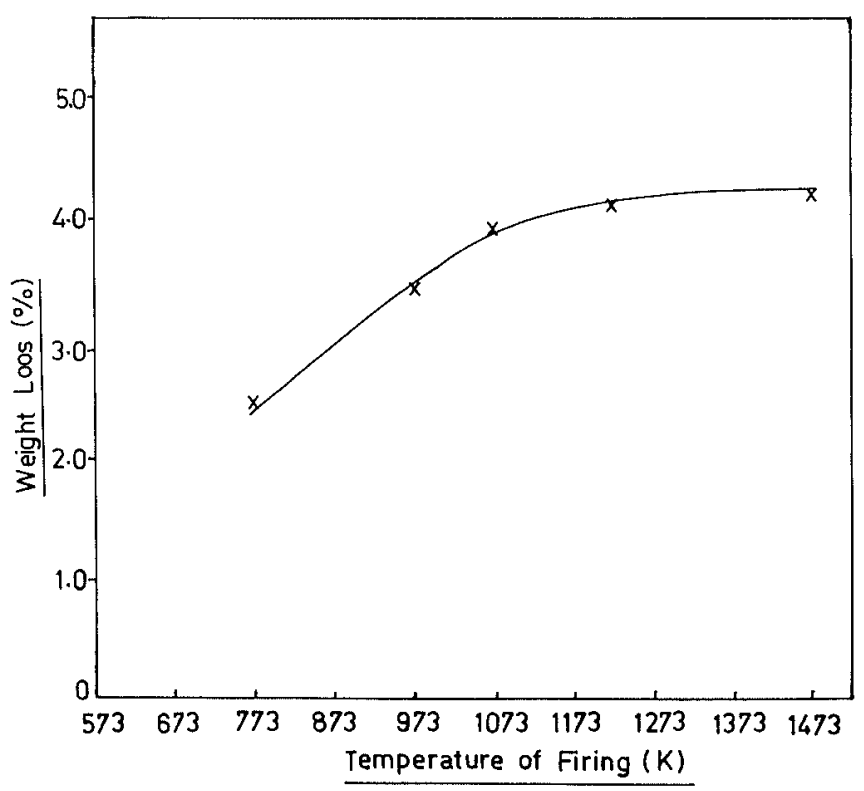

Fig. 10. Weight loss of iron oxide on firing.

the ore.

The decomposition of goethite and other gangue minerals, formation of $\beta-\mathrm{CaSiO}_{3}$ and probably the sintering of intraparticle pores, especially at higher temperature change the density of the powder. These 
Table 5. Variation of thermal diffusivity/conductivity with density/porosity.

\begin{tabular}{cccccccccc}
\hline $\begin{array}{c}\text { Weight of } \\
\text { pellet } \\
(\mathrm{g})\end{array}$ & $\begin{array}{c}\text { Size } \\
(\mathrm{cm})\end{array}$ & $\begin{array}{c}\text { Volume } \\
\left(\mathrm{cm}^{3}\right)\end{array}$ & $\begin{array}{c}\text { Density } \\
\left(\mathrm{m}^{3} / \mathrm{kg}\right)\end{array}$ & $\begin{array}{c}\text { Porosity } \\
(\%)\end{array}$ & $\begin{array}{c}\alpha \\
\left(\mathrm{m}^{2} / \mathrm{s}\right)\end{array}$ & $\begin{array}{c}K \\
(\mathrm{~W} / \mathrm{m} \cdot \mathrm{s})\end{array}$ & $\begin{array}{c}\text { Theoritical } \\
\text { diameter } \\
\text { zero poro. }\end{array}$ & $\begin{array}{c}\text { Ratio of } \\
\text { specific } \\
\text { volume }\end{array}$ & Treatment \\
\hline 3.9043 & 0.6921 & 1.3886572 & 2812 & 35.36 & $3.062 \times 10^{-7}$ & 0.9015 & 0.5983956 & 1.5471820 & Fired at $1233 \mathrm{~K}\left(950^{\circ} \mathrm{C}\right)$ \\
3.9043 & 0.6921 & 1.3886572 & 2812 & 35.36 & $3.025 \times 10^{-7}$ & 0.8903 & 0.5983956 & 1.5471820 & Fired at $1303 \mathrm{~K}\left(1030^{\circ} \mathrm{C}\right)$ \\
5.4500 & 0.7863 & 2.0363543 & 2654 & 38.48 & $2.9875 \times 10^{-7}$ & 0.8301 & 0.6687640 & 1.6253472 & Fired at $\mathrm{I} 303 \mathrm{~K}\left(1030^{\circ} \mathrm{C}\right)$ \\
3.9043 & 0.6839 & 1.3398812 & 2914 & 35.24 & $3.016 \times 10^{-7}$ & 0.9202 & 0.5916715 & 1.5443144 & Fired at $\left[393 \mathrm{~K}\left(1120^{\circ} \mathrm{C}\right)\right.$ \\
2.9585 & 0.61535 & 0.9760119 & 3031 & 32.64 & $3.25 \times 10^{-7}$ & 1.0337 & 0.5394154 & 1.4845563 & Fired at $1473 \mathrm{~K}\left(1200^{\circ} \mathrm{C}\right)$ \\
3.2939 & 0.6360 & 1.0776056 & 3057 & 32.07 & $2.94 \times 10^{-7}$ & 0.9409 & 0.5590745 & 1.4721846 & Fired at $\left[473 \mathrm{~K}\left(1200^{\circ} \mathrm{C}\right)\right.$ \\
3.2939 & 0.6294 & 1.0444036 & 3154 & 33.46 & $2.809 \times 10^{-7}$ & 0.9279 & 0.5494747 & 1.5029232 & Fired at $1488 \mathrm{~K}\left(1215^{\circ} \mathrm{C}\right)$ \\
2.9585 & 0.5854 & 0.8403236 & 3521 & 25.72 & $2.876 \times 10^{-7}$ & 1.0602 & 0.5301532 & 1.3963375 & Fired at $1523 \mathrm{~K}\left(1250^{\circ} \mathrm{C}\right)$ \\
3.5496 & 0.6283 & 1.0389380 & 3416 & 27.93 & $2.9517 \times 10^{-7}$ & 1.0557 & 0.5633402 & 1.3873592 & Fired at $1523 \mathrm{~K}\left(1250^{\circ} \mathrm{C}\right)$ \\
3.5496 & 0.6146 & 0.9724476 & 3650 & 24.27 & $3.025 \times 10^{-7}$ & 1.1560 & 0.5602061 & 1.3204875 & Fired at $1548 \mathrm{~K}\left(1275^{\circ} \mathrm{C}\right)$ \\
3.2939 & 0.6294 & 1.0444036 & 3154 & 33.46 & $2.7425 \times 10^{-7}$ & 0.9056 & 0.5494747 & 1.5029232 & Fired at $1488 \mathrm{~K}\left(1215^{\circ} \mathrm{C}\right)$ \\
2.9505 & 0.61535 & 0.9760119 & 3031 & 32.64 & $3.045 \times 10^{-7}$ & 0.9668 & 0.5394154 & 1.4045563 & Fired at $1473 \mathrm{~K}\left(1200^{\circ} \mathrm{C}\right)$ \\
\hline
\end{tabular}

Table 6. Variation of thermal diffusivity/conductivity with density/porosity (Pure iron oxide).

\begin{tabular}{cccccccccc}
\hline $\begin{array}{c}\text { Weight of } \\
\text { pellet } \\
(\mathrm{g})\end{array}$ & $\begin{array}{c}\text { Size } \\
(\mathrm{cm})\end{array}$ & $\begin{array}{c}\text { Volume } \\
\left(\mathrm{cm}^{3}\right)\end{array}$ & $\begin{array}{c}\text { Density } \\
\left(\mathrm{m}^{3} / \mathrm{kg}\right)\end{array}$ & $\begin{array}{c}\text { Porosity } \\
(\%)\end{array}$ & $\begin{array}{c}\alpha \\
\left(\mathrm{m}^{2} / \mathrm{s}\right)\end{array}$ & $\begin{array}{c}K \\
(\mathrm{~W} / \mathrm{m} \cdot \mathrm{s})\end{array}$ & $\begin{array}{c}\text { Theoritical } \\
\text { diameter } \\
\text { zero poro. }\end{array}$ & $\begin{array}{c}\text { Ratio of } \\
\text { specific } \\
\text { volume }\end{array}$ & Treatment \\
\hline 2.6393 & 0.5756 & 0.7988234 & 3304 & 30.44 & $2.756 \times 10^{-7}$ & 0.9534 & 0.5099983 & 1.43766 & Fired at $1523 \mathrm{~K}\left(1250^{\circ} \mathrm{C}\right)$ \\
2.6393 & 0.5756 & 0.7988234 & 3304 & 30.44 & $2.782 \times 10^{-7}$ & 0.9624 & 0.5099983 & 1.43766 & Fired at $1523 \mathrm{~K}\left(1250^{\circ} \mathrm{C}\right)$ \\
3.7530 & 0.6690 & 1.2542004 & 2923 & 38.46 & $2.50 \times 10^{-7}$ & 0.7651 & 0.5734982 & 1.58739 & Fired at $1473 \mathrm{~K}\left(1200^{\circ} \mathrm{C}\right)$ \\
3.7530 & 0.6490 & 1.1450451 & 3278 & 30.99 & $2.649 \times 10^{-7}$ & 0.9074 & 0.5734982 & 1.44923 & Fired at $1498 \mathrm{~K}\left(1225^{\circ} \mathrm{C}\right)$ \\
2.6393 & 0.5672 & 0.7643585 & 3453 & 27.31 & $2.704 \times 10^{-7}$ & 0.9776 & 0.5099983 & 1.37563 & Fired at $1598 \mathrm{~K}\left(1275^{\circ} \mathrm{C}\right)$ \\
\hline
\end{tabular}

True density of Iron Oxide Powder $4750 \mathrm{~kg} / \mathrm{m}^{3}$.

density values were taken as true densities to calculate porosity of pellet after firing at appropriate temperatures. The measured density values are

$\begin{array}{lc}\text { Temperature } & \text { Density }\left(\mathrm{kg} / \mathrm{m}^{3}\right) \\ 1223-1303 \mathrm{~K} & 4350 \\ 1393-1473 \mathrm{~K} & 4500 \\ 1388-1523 \mathrm{~K} & 4740 \\ 1448 \mathrm{~K} & 4820\end{array}$

Table 6 indicates the values of thermal diffusivities with pellet density, porosity, and corresponding thermal conductivities alongwith the thermal treatment given. The thermal conductivities are calculated by taking ${ }^{21)}$ the true heat capacity value of iron oxide at $973 \mathrm{~K}\left(700^{\circ} \mathrm{C}\right)$ as $1.047 \mathrm{~kJ} / \mathrm{kg} \mathrm{K}^{21 \text { ) }}$

\subsection{Model Fitting}

A simple expression for effective thermal conductivity of iron ore pellet to its porosity is useful in solving the heat transfer problems. Many expressions used for iron ore agglomerates are listed by Akiyama ${ }^{8)}$ and co-workers. They explained their results by applying unit cell model originally proposed by Luikov. In the present investigation attempts were made to correlate the effective thermal conductivity ' $K_{\mathrm{e}}$ ' and porosity ' $e$ ' by different model equations available. The radiative heat transfer within pore is neglected. The equations tried are
(a) $K_{\mathrm{e}}=e \cdot K_{\mathrm{g}}+(1-e) K_{\mathrm{s}}$
(b) $K_{\mathrm{e}}=\left[e / K_{\mathrm{g}}+(1-e) / K_{\mathrm{s}}\right]^{-1}$
(c) $K_{\mathrm{e}}=K_{\mathrm{s}}^{1-e} \cdot K_{\mathrm{g}}^{e}$

(d) $K_{\mathrm{e}} / K_{\mathrm{s}}=(1-2 e(P-1) /(2 P+1)) /$

$$
(1+e(P-1) /(2 P+1))
$$

(e) $K_{\mathrm{e}} / K_{\mathrm{s}}=\left(e^{2 / 3}+P\left(1-e^{2 / 3}\right)\right) /$

$$
\left(e^{2 / 3}-e+P\left(1-e^{2 / 3}+e\right)\right)
$$

where, $K_{\mathrm{s}}$ : thermal conductivity of pellet with zero porosity,

$\begin{array}{ll}K_{\mathrm{g}}: & \text { thermal conductivity of gas in pore, } \\ P: & K_{\mathrm{s}} / K_{\mathrm{g}} .\end{array}$

Figure 11 indicates the experimental points of thermal conductivities with porosity of the pellets along with calculated values of effective thermal conductivity by Eqs. (14) and (15). The variation of ' $K_{\mathrm{e}}$ ' with porosity computed by Eq. (11) is too low and that by Eq. (13) is too sharp to explain present experimental values. However, it could be noticed from the figure that values computed by Eqs. (14) and (15) fits in satisfactorily for ' $K_{\mathrm{s}}$ ' values of 1.55 to $1.60 \mathrm{~W} \cdot \mathrm{m}^{-1} \cdot \mathrm{s}^{-1}$ for Eqs. (14) and (15), repectively. The thermal conductivity of air for these calculations were $\operatorname{taken}^{22)}$ as $0.06 \mathrm{~W} \cdot \mathrm{m}^{-1} \cdot \mathrm{s}^{-1}$. Equation (14) is a better fit out of the two equations. It could also be observed that the present experimental values of effective thermal conductivities increases more sharply with the decrease in porosity than those predicted by these models. This aspect motivated us to analyse the results further by using basic sintering equation available in literature.

The process of sintering of fine powders were widely investigated in powder metallurgy. Various mechanisms were proposed and activation energies calculated. ${ }^{23,24)}$ The sintering behaviour of iron oxide in specific were 
reported by Misra, ${ }^{25)}$ Seshadri ${ }^{26)}$ and Wynnyckyj. ${ }^{18)}$ The representation of densification of pellet with parameters which approach ' 1 ' on sintering to theoretical density were used to interpret sintering kinetics. Use of volume ratios by Tikkanen ${ }^{27}$ to explain sintering of metal powders and by Wynnyckyj ${ }^{18)}$ for iron ore pellets are reported in literature. Wynnyckyj ${ }^{18)}$ even co-related the crushing strength of pellet to volume shrinkage ratio and to percent theoretical density of pellet. With the same logic, an attempt has been made in present investigation to correlate the thermal conductivity to ratio of volume of pellet to its volume at zero porosity. The results for

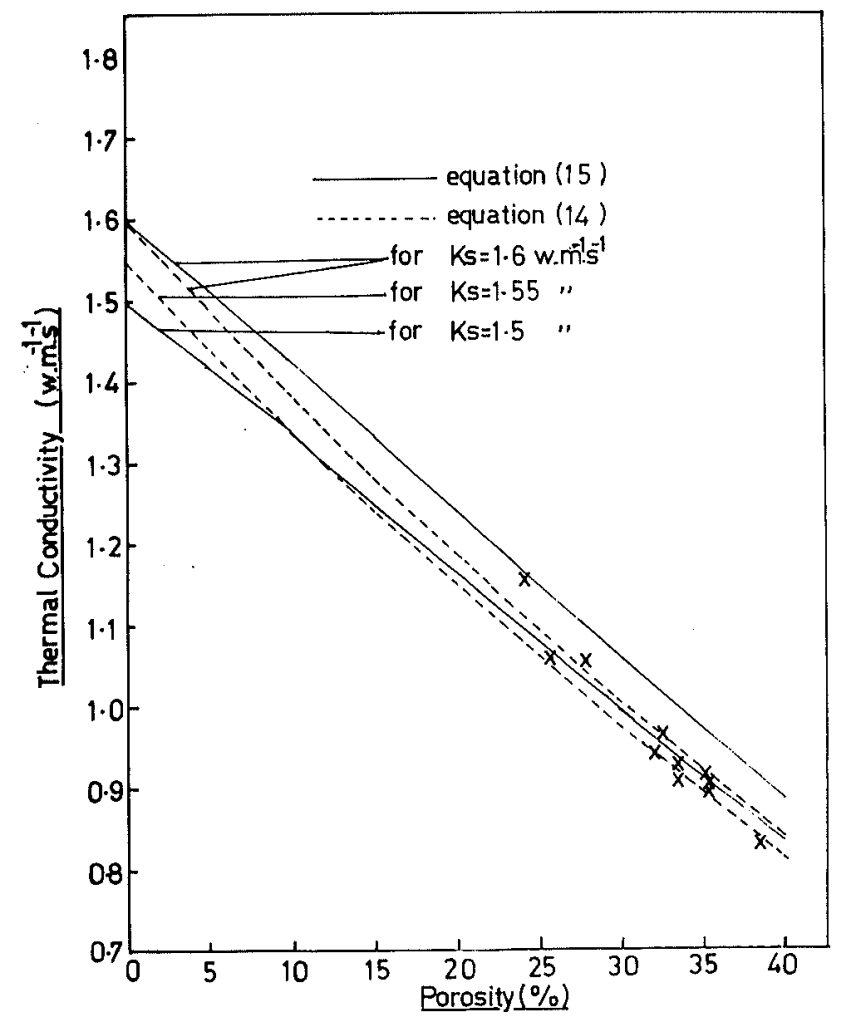

Fig. 11. Variation of thermal conductivity with porosity and model fitting.

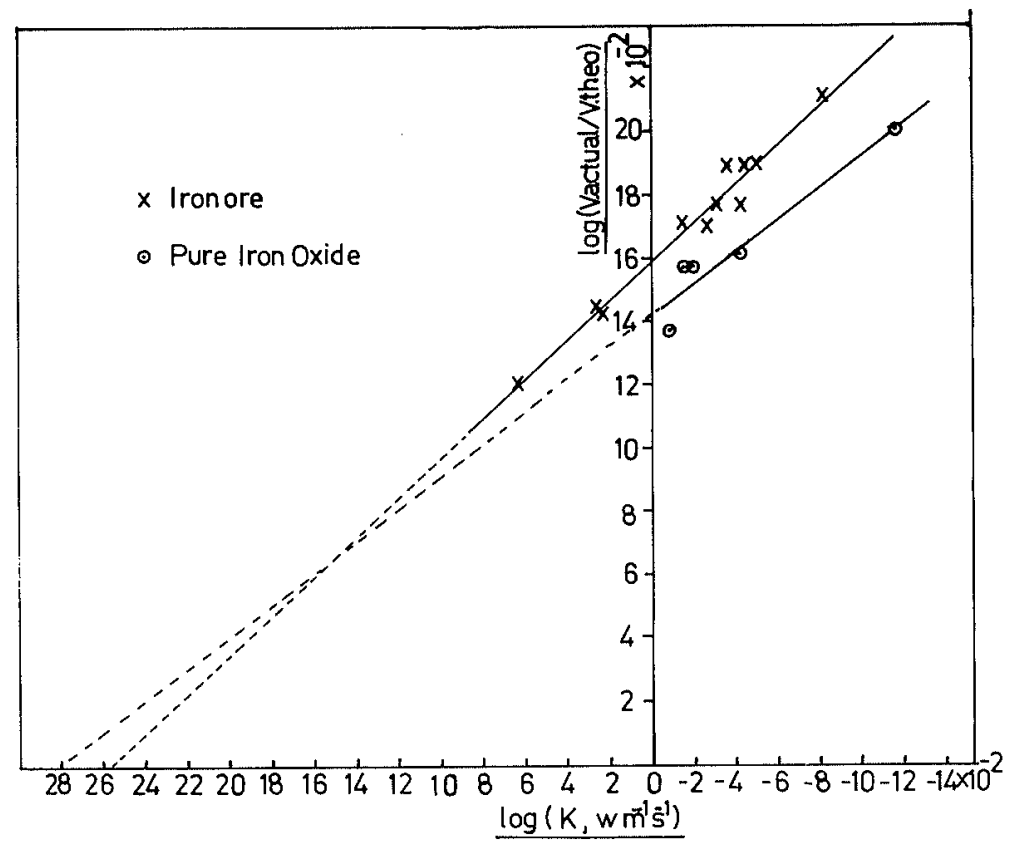

Fig. 13.

Log- $\log$ plot between thermal conductivity and volume ratio. iron ore pellets and pure iron oxide pellets are indicated in Fig. 12. The extrapolation of the plot to ratio of ' 1 ' will lead to the value of ' $K_{\mathrm{s}}$ '. The $\log / \log$ plot for same results is indicated in Fig. 13 and the intercept values are calculated by least square method for better accuracy. The values of ' $K_{\mathrm{s}}$ ' thus found for iron ore is $1.81 \mathrm{~W} \cdot \mathrm{m}^{-1} \cdot \mathrm{s}^{-1}$ at $973 \mathrm{~K}$ and $1.90 \mathrm{~W} \cdot \mathrm{m}^{-1} \cdot \mathrm{s}^{-1}$ for pure iron oxide pellets. Limited number of points, in case of pure oxide is due to less quantity of synthesised material available. The pellets were hand rolled in this case.

\section{Conclusion}

(1) The iron ore from Rajhara mine of India contains goethite alongwith hematite. On firing goethite decompose and on reaction $\beta-\mathrm{CaOSiO}$ is formed.

(2) The decomposition of goethite and other gangue minerals along with formation of $\mathrm{CaOSiO}_{2}$ changes the

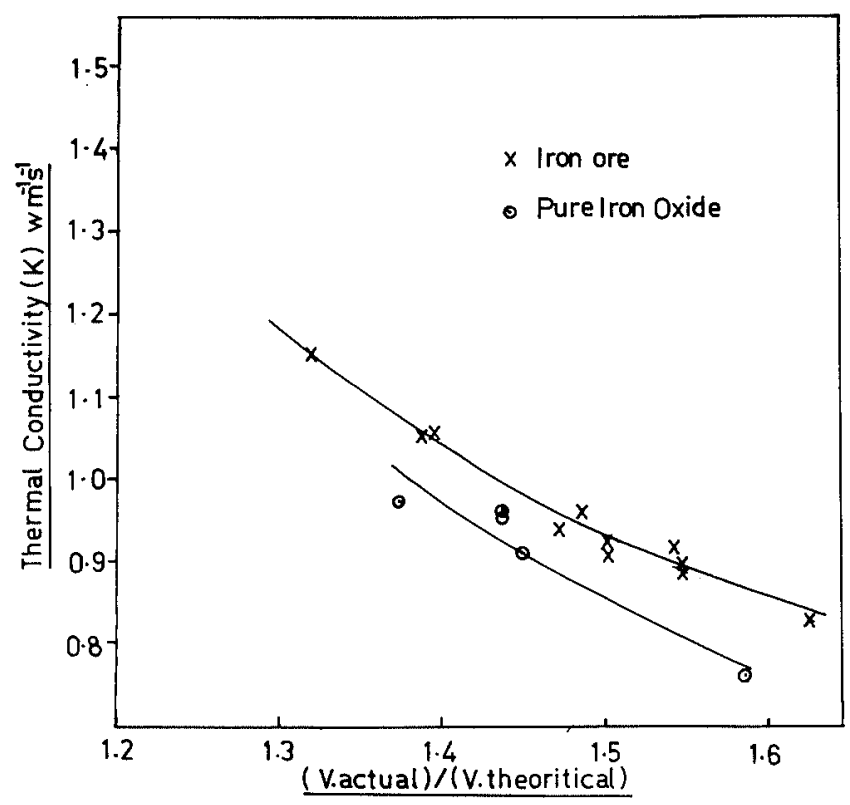

Fig. 12. Variation of thermal conductivity with volume ratio. 
density of powder.

(3) The thermal diffusivity and effective thermal conductivity of iron oxide pellets for radial heat flow can be determined by calculating average heating rate and applying heat balance. The result are comparable to those given in literature.

(4) The decrease in effective thermal conductivity with increase in porosity could be explained satisfactorily by model Eqs. (14) and (15) in the text.

(5) The effective thermal conductivity at zero porosity of the pellet could be determined more accurately by using basic shrinkage parameters and densification.

(6) The value of effective thermal conductivity at zero porosity iron ore pellet is $1.81 \mathrm{~W} \cdot \mathrm{m}^{-1} \cdot \mathrm{s}^{-1}$ and for pure iron oxide pellet is around $1.9 \mathrm{~W} \cdot \mathrm{m}^{-1} \cdot \mathrm{s}^{-1}$.

\section{REFERENCES}

1) J. R. Wynnyckyj and W. A. McCurdy: Metall. Trans., (1974), 2207.

2) E. C. Seaton, J. S. Foster and J. Velasco: Trans. Iron Steel Inst. Jpn., 23 (1983), 490.

3) S. K. Misra and V. K. Jain: J. Inst. Eng., (India), Metall. Mater. Sci., 67 (1986), 17.

4) I. E. Campbell and E. M. Sherwood: High Temperature Materials and Technology, John Wiley, New York, (1967), 960.

5) H. Ohta, T. Akiyama, I. Suh, R. Takahashi, J. Yagi and Y. Waseda: Tetsu-to-Hagané, 75 (1989), 1877.

6) T. Akiyama, G. Ogura, H. Ohta, R. Takahashi and J. Yagi: Tetsu-to-Hagané, 77 (1991), 231.

7) T. Akiyama, R. Takahashi and J. Yagi: ISIJ Int., 31 (1991), 24.

8) T. Akiyama, H. Ohta, R. Takahashi, Y. Waseda and J. Yagi: ISIJ Int., 32 (1992), 829.

9) V. M. Abzalov, B. P. Yuryev and S. G. Bratchikov: IZV Akad
Nauk USSR, Metally (1976), No. 6, 10-7; Russian Metall., (1976), No. 6, 9-15.

10) A. Watts, J. K. Wright and J. Vale: Trans. Inst. Min. Metall., 89 (1980), c192.

11) A. Watts and J. K. Wright: Trans. Inst. Min. Metall., 91 (1982), C18.

12) Selected Powder Diffraction Data, JCPDS, Card No. 13-534, $19-249,17-536$.

13) H. S. Ray: Proc. Symp. Advances in Chemical Metallurgy DAE, Bombay, (1979), 43/11/18.

14) J. Szekely and N. J. Themelis: Rate Phenomena in Process Metallurgy, Wiley Interscience, New York, (1971), 203.

15) H. S. Carslow and J. C. Jaeger: Conduction of Heat in Solids, Oxford University Press, London, (197I), 203

16) The Making Shaping and Treating of Steel, ed. by H. E. McGannon, USS, Pittsburg, (1964), 304.

17) J. I. Laybidi, A. K. Bhattacharya and Prakash: Proc. Advances in Chemical Metallurgy, ed. by C. K. Gupta and M. K. Totlani, I.I.M. Material Div., Bombay, (1991), 325.

18) J. R. Wynnyckyj and T. Z. Fahidy: Metall. Trans., 5 (1974), 991.

19) Y. H. Yang and N. Standish: ISIJ Int., 31 (1991), 468

20) M. I. Nasr, A. A. Omar and M. E. H. Shalabi: J. Inst. Eng. (India), 75 (1994), 79

21) E. I. Kazantsev: Industrial Furnaces, Mir Pub., Moscow, (1977), 124.

22) R. T. L. Guthrie; Engineering in Process Metallurgy, Clarendon Press, Oxford, (1989)

23) F. Thummler and W. Thomma: Metals and Materials and Metallurgical Review, (1967), 69

24) A. Mohan, N. C. Soni and V. K. Moorthy: Trans. Indian Inst. Met., 33 (1980), 423

25) U. N. Mishra and P. K. Sen: Trans Indian Inst. Met., 32 (1979), 411.

26) G. L. Misra, A. R. Das and V. Seshadri: Trans. Iron Steel Inst. Jpn., 11 (1971), 323.

27) H. F. Exner and G. Petzow: Sintering Processes, Material Sc. Research Vol. 13, ed. by G. C. Kuczynski, 113. 